\title{
PEMANFAATAN TUMBUHAN DIWOKA (Piper macropiper Pennant.) OLEH SUKU DANI, WAMENA
}

\author{
Konstantina M.B. Kameubun ${ }^{1)}$; Rosania Rehiara ${ }^{2)}$; Frans Deminggus ${ }^{3)}$ \\ ${ }^{1}$ Program Studi Pendidikan Biologi FKIP UNCEN; brigitabio@yahoo.co.id. \\ ${ }^{2}$ Program Studi Pendidikan Biologi FKIP UNCEN; rosa.rehiara@yahoo.com \\ ${ }^{3}$ Program Studi Pendidikan Kimia FKIP UNCEN; fransdeminggus@yahoo.co.id
}

\begin{abstract}
Ethnobotanical and taxonomical studies are conducted to uncover the scientific name, uses as well as utilization of Diwoka (local name) popular to the Dani people in Wamena. The local name, Diwoka, is determined by its scientific name Piper macropiper Pennant. Piper macropiper has been used by the Dani people to serve as spices when foods are cooked traditionally by stone-fired earth oven (bakarbatu) or prepared in other ways such as stir-frying vegetables, fish, and meat. The leaves can be consumed uncooked the way salad is consumed beside it is functioned as medicine as well. The distribution of this type of plant is found in Indonesia, Papua New Guinea, Solomon Islands, Australia (Northern territory), Brunei, and Sri Lanka
\end{abstract}

Key words: Diwoka Plant (Piper macropiper Pennant.); Dani; Wamena; Papua

\begin{abstract}
ABSTRAK
Kajian etnobotani dan taksonomi bertujuan untuk mengungkap nama ilmiah dan pemanfaatan serta manfaat dari tanaman Diwoka (nama lokal) yang dikenal oleh masyarakat suku Dani di Wamena. Nama lokal Diwoka tersebut terdeterminasi nama ilmiahnya yaitu Piper macropiper Pennant. Piper macropiper digunakan oleh masyarakat suku Dani di Wamena sebagai bumbu masak yang dimasak dengan cara tradisional masyarakat suku Dani yaitu Bakar Batu dan cara lainnya seperti tumis sayursayuran, tumis ikan maupun daging. Daun tersebut dapat dimakan mentah secara langsung seperti layaknya sayur lalapan dan sebagai obat. Distribusi tanaman ini terdapat di Indonesia, Papua New Guinea, Solomon Islands, Australia (Northern territory), Brunei dan Sri Lanka.
\end{abstract}

Kata Kunci: Tumbuhan Diwoka (Piper macropiper Pennant.); Dani; Wamena; Papua

\section{PENDAHULUAN}

Masyarakat suku Dani di Wamena Kabupaten Jayawijaya menggunakan salah satu tanaman yang dikenal dengan nama lokal Diwoka dari genus Piper sebagai bumbu masak dengan cara memasak Bakar Batu (salah satu cara memasak tradisional suku Dani). Kemungkinan, ada manfaat serta potensi lain yang dimiliki oleh Diwoka (Piper macropiper Pennant) yang dapat digali untuk diketahui dan digunakan oleh para ilmuan untuk melakukan penelitian dengan aspek lain yang belum terungkap.

Gagasan untuk mendapatkan dimensi baru dalam memanfaatkan pengetahuan masyarakat tradisional (Indigenous knowledge) disadari bahwa pengetahuan masyarakat ini telah memberi warna dan sumbangan terhadap kemajuan 
dunia akan ilmu pengetahuan dan teknologi. Banyak ilmuwan akhir-akhir ini mulai tertarik untuk mengkaji pengetahuan masyarakat lokal serta pemahaman alam sekitar oleh masyarakat setempat. Kenyataan ini membuktikan bahwa pengetahuan masyarakat yang telah teruji secara turun temurun tidak sedikit sumbangannya terhadap kemajuan ilmu dan teknologi.

Pengetahuan tradisional dapat diungkapkan melalui penelitian etnobotani di setiap suku bangsa di Indonesia pada umumnya dan Papua pada khususnya. Pengungkapan tradisional tersebut sangat penting dan mendesak untuk segera dilaksanakan. Diharapkan pengetahuan tradisional (Indigenous knowledge) masyarakat suku Dani di Wamena Kabupaten Jayawijaya yang memanfaatkan tanaman Diwoka (Piper macropiper Pennant.) dapat dipakai sebagai petunjuk dalam menganalisa tanaman tersebut lebih mendalam (mengadopsi pengetahuan tradisional (Indigenous knowledge) yang selanjutnya dapat dipergunakan untuk sains dalam mencari peluang lain atau peluang baru pemanfaatan tanaman Diwoka (Piper macropiper Pennant.) sebagai vahan dasar obat-obatan dan bumbu lokal Indonesia.

Bagaimana pengetahuan masyarakat suku Dani dan masyarakat lain di Wamena mengenal, membedakan, membudidayakan, memanfaatkan dan melestarikan tanaman Diwoka (Piper macropiper Pennant.) menjadi tujuan dari penelitianini, selain itu ingin mengetahui dimana saja persebaran tanaman Pipersp di daerah Wamena Kabupaten Jayawijaya dan keselurahan daerah yang terdapat di Papua, keseluruhan pulau yang terdapat di Indonesia, dan keseluruhan pulau di dunia.

\section{METODE PENELITIAN}

Kajian untuk mengungkapkan pengetahuan tradicional masayarakat suku Dani menggunakan 2 pendekatan utama yaitu pendekatan Emik dan Etik (Walujo, 1998: Walujo, 2004). Pendekatan Emik adalah pendekatan berdasarkan pendekatan penelitian ethnology untuk mendapatkan suatu deskripsi tantang persepsi dan konsep dari masyarakat lokal yang menjadi objek penelitian. Pendekatan Etnik adalah pendekatan yang digunakan dalam menganalisis persepsi dan konsepsi masyarakat yang dicoba untuk dibuktikan berdasarkan kaidah ilmu pengetahuan secara ilmiah, yaitu biologi (taksonomi).

Teknik pengambilan sampel dan data dengan melakukan Survey, observasi partisipasi dan wawancara yang dilakukan dibeberapa Kampung yaitu Napua, Wamena Kota, Kurulu, Walesi, Putagaima dan orang suku Dani yang berada di Kurima dan Habema yang berjualan di pasar Wouma yang berdasarkan administratif geografister masuk dalam Kabupaten Mamberamo Tengah pada saat 
ini yang sebelumnya masih termasuk Kabupaten Jayawijaya.

$$
\text { Wawancara dilakukan kepada }
$$
masyarakat asli suku Dani Kabupaten Jayawijaya per individu. Wawancara bersifat semistruktural yang berpedoman pada daftar pertanyaan (kuisioner sederhana) sebagai pengontrol bagi peneliti untuk mengajukan pertanyaan kepada nara sumber sebagai informan kunci, dan wawancara open-ended. Jumlah narasumber yang menjadi informan kunci sebanyak 100 orang yang terdiri dari para orangtua, orang dewasa dan anak-anak baik pria maupun wanita. Informasi yang berasal dari para informan dicatat dan sampel tanaman Diwoka dibuat Herbarium kering dan diidentifikasikan di Herbarium Bogoriense, Bogor.

Data koleksi spesimen herbarium dari berbagai lembaga herbarium antara lain: Herbarium Bogoriense, National Herbarium Nedtherland, Australia National Herbarium (CANB), Nationla Herbarium of New South Wales, Missouri Botanical Garden (MO Herbarium) dan studi literatur digunakan untuk mengetahui persebaran tanaman Diwoka (Piper macropiper Pennant.) di dunia

\section{HASIL DAN PEMBAHASAN}

\section{Taksonomi}

\section{Determinasi}

Hasil identifikasi tumbuhan Diwoka (Piper sp) yang berasal dari Wamena,
Papua adalah Piper macropiper Pennant. dari famili Piperaceae (gambar 1):

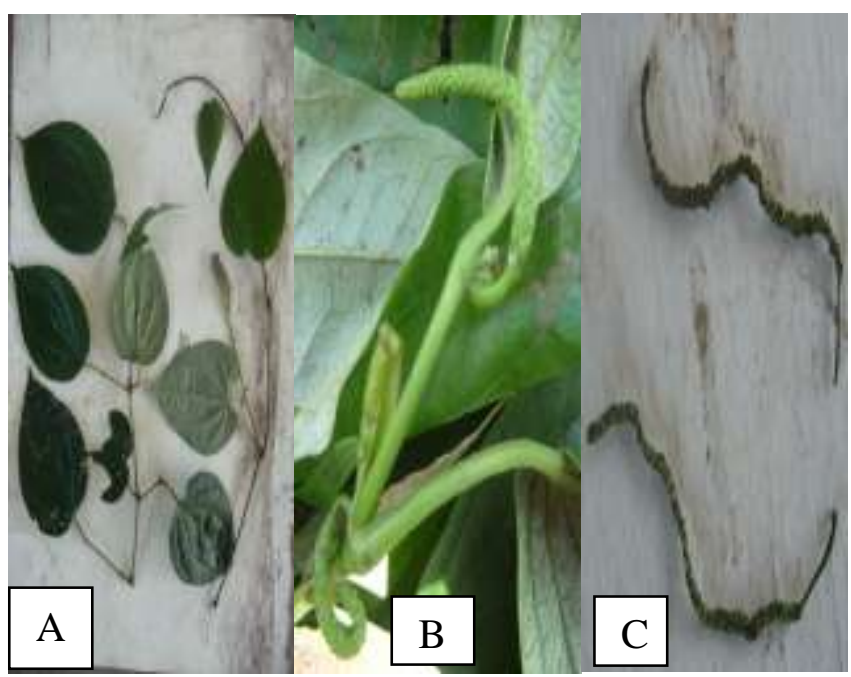

Gambar 1: (A) Piper macropiper Pennant. (B) Buah Yang Masih Sangat Muda.(C) Buah Yang Sudah Dewasa.

\section{Sinonim}

Piper macropiper sinonim dengan:

1. Piper rothiana F.M.Bailey,

2. Pipervaupelii Lauterb.

\section{Nama Lokal (Vernacular Name)}

Tanaman Piper macropiper Pennant. memiliki beberapa nama daerah atau nama lokal (vernacular name) yang berbeda antar kampung di Wamena masyarakat di kampung Habema menyebut dengan nama Libongga, Kurima dengan nama Labet, Walesi dan Wamena dengan nama Diwoka

\section{Deskripsi Piper macropiper Pennant. dari Wamena}

Habitat di tempat yang lembab, di hutan yang masih rimbun dengan pepohonan. Habitus berupa liana yang merambat ketika masih muda dan menurut Priyono dan Jamal (2008), ketika masih muda berupa liana yang merambat dan membentuk semak tegak dengan ciri 
batang yang mengeras dan berkayu ketika dewasa atau mencapai umur tahunan. Batang licin warna hijau kecoklatan, dapat bercabang menjadi beberapa ranting dari batang pokok. Daun tunggal, duduk daun berselang seling pada batang dan ranting, daun berstipula pada tepi dari upih daun, panjang stipula 8-20 $\mathrm{mm}$, melekat pada dasar tangkai daun pada daun muda tapi segera layu dan gugur, helaian daun berwarna hijau, lunak, berbentuk jantung dan lonjong panjang/oval, sekitar 8-20 cm x 4-10, panjang tangkai daun $0.5-1.5 \mathrm{~cm}$ terjadi perubahan bentuk dan sifat daun; daun muda berbentuk jantung hati warna hijuau mudah dan sangat lunak sehingga dapat dimakan langsung seperti makan lalapan terasa pedis, dan berubah menjadi lonjong/oval dengan pangkal membulat dan ujung meruncing, berwarna hijau agak gelap pada daun yang tua, agak keras dan kaku, daun berbau aromatik khas bau sirih tetapi lebih tajam dari pada bau pada daun Piper betle, tulang daun melengkung mengikuti panjangnya daun dari pangkal ke ujung, ujung daun meruncing. Buahnya seperti buah sirih tetapi sangat kecil berwarna hijau pada saat masih muda, panjang bulir $6 \mathrm{~cm}$ atau lebih.

\section{Ekologi}

Piper macropiper tumbuh dengan baik pada daerah yang lembab dan dingin, pada ketinggian $1700-1878$ m dari permukaan laut (dpl). Tidak dapat tumbuh pada daerah yang panas.

\section{Distribusi Piper macropiper Pennant.}

Berdasarkan data spesimen herbarium dari beberapa lembaga herbarium diketahui penyebaran tanaman Diwoka (Piper macropiper) terdapat di beberapa negara di dunia antara lain: Indonesia, PNG, Solomon, Sri Lanka, Brunei, Filipina, Australiadan menurut Gardner (2006), distribusi Piper macropiper Pennant dapat ditemukan di Taiwan, Philippines dan Tenggara Malay Peninsula ke kepulauan Solomon dan Australia.

Negara Indonesia yang terdiri dari 17.000 pulau hanya 2 pulau yaitu Papua dan Sulawesi yang ditemukan tanaman Piper macropiper. Kedua pulau tersebut yaitu Papua terdapat di (Kabupaten Jayawijaya antara lain: Habema, Kurima, Wamena, Walesi, Napau), (Kabupaten Raja Ampat antara lain: Kampung Warsamdin Teluk Mayalibit, Waigeo), (Sorong: Lawarere, Ayamaru), (Kabupaten Jayapura di Pegunungan Cycloop), dan (Pegunungan Arfak, Manokwari).

Bila dilihat berdasarkan ras, wilayah Negara Indonesia terdiri dari ras Indo-Malayo dan ras Melanesia. Ras IndoMalayo terdiri atas pulau-pulau antara lain Sumatera, Jawa, Kalimantan, Sulawesi, Nusa Tenggara Barat, Nusa Tenggara Timur,dan Maluku. Sedangkan Ras Melanesia terdiri atas pulau Papua. Kawasan yang termasuk dalam ras IndoMalaysia yang merupakan kawasan 
Jurnal Ilmu Pendidikan Indonesia 8 (1) : 37 - 45 | 41

Malayo. Dengan diketahui tanaman Pipermacropiper yang ditemukan di pulau Sulawesi dan Papua maka penyebaran dari tanaman tersebut ditemukan di ras IndoMalayo dan Melanesia. Dengan demikian penyebaran yang mencakup kawasan Malayo-Oceania dapat ditemukan pada kedua daerah tersebut (Gambar 2). Penyebaran Piper macropiper Pennant. berbeda dengan penyebaran Piper methysticum yang hanya ditemukan di wilayah ras Melanesia yang hanya mencakupkawasan Oceania (Gambar 3) (Kameubun, 2003 dan 2014) :

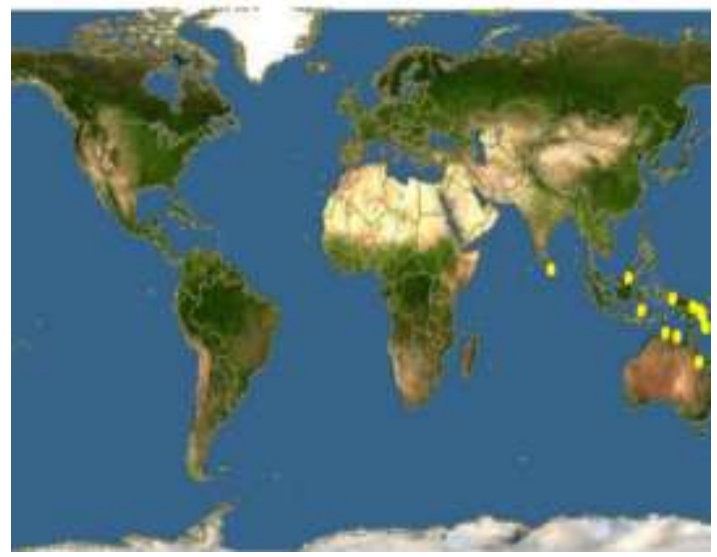

Gambar 2 : Distribusi Piper Macropiper di Dunia. Sumber: Encyclopedia of life (Eol).

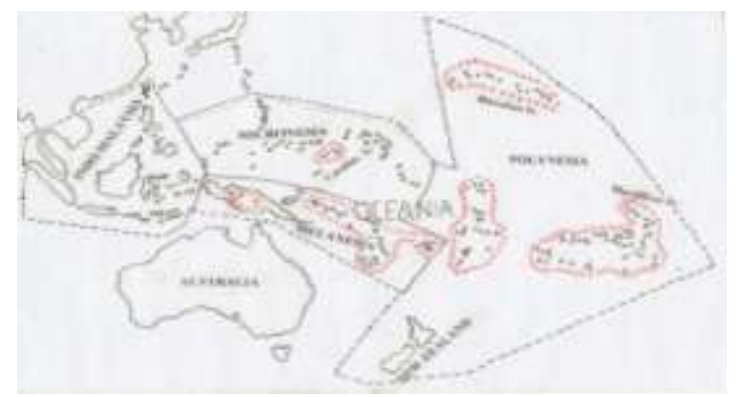

Gambar 3: Distribusi Piper Methysticum Forst. di dunia. Sumber: Kameubun, 2003 dan 2014.

Penyebaran tanaman Piper macropiper Pennant. di Papua berdasarkan data spesimen menunjukan bahwa tanaman tersebut penyebarannya hanya di daerah
Jayapura, Wamena, Manokwari dan Sorong. Kemungkinan peyebaran dari tanaman ini dapat ditemukan ditempat lain bila melakukan survey di tempat-tempat lain di Papua (gambar 4). Bila dibandingkan penyebaran tanaman Piper macropiper dengan Piper methysticumdi Papua maka hanya Wamena yang merupakan tempat dimana kedua tanaman ini dapat ditemukan. Kameubun (2003 dan 2014) menyatakan bahwa persebaran tanaman Piper methysticum Forst terdapat di Merauke, dan daerah Papua lainnya yaitu di jalan setapak Komopa dekat Enarotali, Tembagapura dan desa Wurigelebur kecamatan Kelila Kabupaten Wamena (Gambar 5);

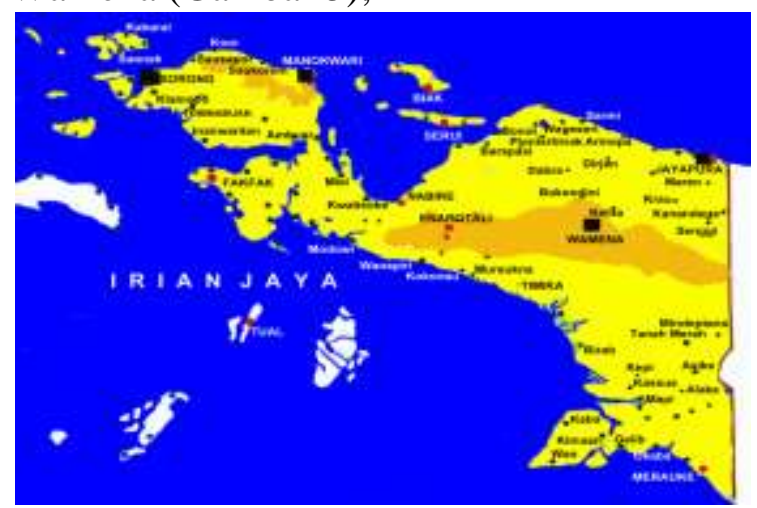

Gambar 4: Peta Penyebaran Piper macropiper Pennant. di Papua (Kotak Hitam merupakan Daerah yang ditemukan Spesis Piper Macropiper Pennant.)

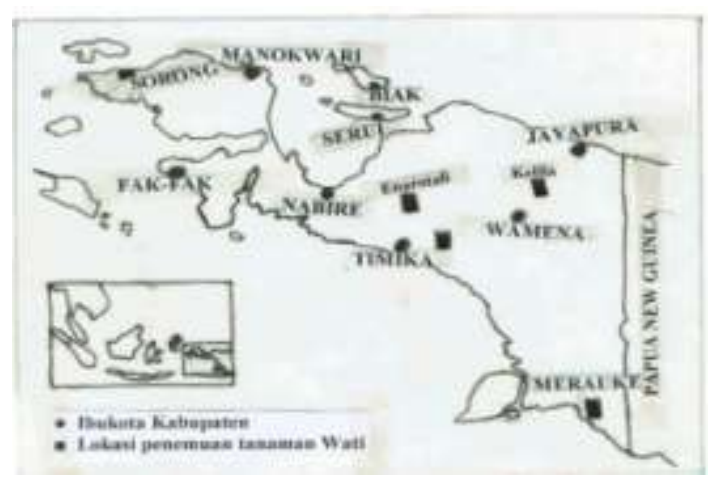

Gambar 5: Peta Penyebaran Piper Methysticum Forst. di Papua 
2. Pandangan, Pengetahuan dan Penggunaan Tanaman Piper macropiper Pennant. Dalam kehidupan suku Dani.

Masyarakat suku Dani mengenal dan menggunakan tumbuhan Piper macropiper dalam kehidupan sehari-hari. Tidak ada keistimewaan atau sesuatu yang bersifat sakral untuk tumbuhan ini oleh suku Dani, seperti halnya Wati (Piper methysticum Forst.) di Merauke yang oleh masyarakat suku Marind memandang dan memperlakukan tanaman Wati (Piper methysticum Forst.) sangat istimewa dan sakral (Kameubun, 2003). Masyarakat Dani yang bermukim di Wamena memberikan nama Diwoka untuk tumbuhan Piper macropiper dengan arti "Diwo" adalah nama dari tanaman tersebut dan "ka" adalah daun.

\section{Pemanfaatan Tanaman Diwoka (Piper macropiper Pennant.)}

Tumbuhan yang dikenal dengan nama Diwoka, Libongga, dan Labet oleh masyarakat suku Dani dengan nama ilmiah (scientific name) Piper macropiper Pennant. dimanfaatkan sebagai sayur lalapan, pada daun yang masih sangat muda, bumbu sebagai pengganti daun salam dan sebagai penyedap masakan, dan sebagai obat sariawan, badan tidak enak layaknya demam atau malaria, menambah gairah makan yang disebabkan karena mulut terasa tidak enak untuk makan (kurang bernapsu untuk makan) dan menambah stamina sehingga badan yang terasa sakit akan menjadi lebih kuat dan segar. Bagian tanaman yang digunakan adalah hanya daun.

Cara mengolah untuk masingmasing kegunaan dibahas secara detail dibawah ini:

Sayur lalapan: daun yang muda di cuci dan dimakan langsung dengan garam seperti halnya lalapan.

Bumbu: daun yang digunakan dapat berupa daun segar ataupun daun yang sudah dikeringkan dengan sinar matahari atau angin. Daun tersebut dapat diolah untuk menumis sayur ataupun daging dan ikan atau masakan lainnya. Daun tersebut sama fungsinya seperti daun salam yang akan memberikan keharuman pada masakan. Tradisi orang suku Dani dalam masak memasak yaitu bakar batu yang terdiri dari umbi-umbian, sayur-sayuran dan daging terutama daging babi akan menggunakan daun Piper macropiper sebagai bumbu pada beberapa bahan makanan yang sudah dimasak dengan cara bakar batu. Caranya: daun Piper macropiper diremas sedikit sehingga layu dan mengeluarkan cairan dan aroma yang sangat tajam, dicampur dengan garam, vetsin, bawang, lalu dimakan dengan potongan-potongan daging ataupun sayursayuran dari hasil masak dengan cara bakar batu. 
Obat Sariawan: bagi orang yang menderita sakit Sariawan dapat diobati dengan daun tanaman Piper macropiper yang masih mudah. Daun tersebut dimakan secara langsungatau dapat pula dimakan bersama dengan daging, dan sayuransayuran lainnya.

\section{Nilai Jual}

Tanaman Piper macropiper memiliki nilai jual dipasar wamena. Ibu-ibu atau anak-anak menjual ikatan-ikatan daun yang masih segar di pasar tradisional di Wamena dengan harga Rp 5.000,00 untuk ikatan yang kecil dan Rp 10.000,00 untuk ikatan yang lebih besar (gambar 6). Nilai jual dari tanaman ini masih terbatas pada penjualan daun segar di pasar-pasar di Wamena oleh masyarakat asli suku Dani dan Lani. Sampai saat ini belum ada usaha untuk mengembangkan tanaman ini menjadi suatu produk yang memiliki daya jual yang lebih tinggi dari nilai jual daun segar dipasar Wamena. Nilai jual tanaman Diwoka (Piper macropiper) oleh masyarakat suku Dani di Wamena lebih rendah dibandingkan dengan nilai jual tanaman Wati Piper methysticum yang dimanfaatkan sebagai minuman yang disediakan dalam setiap acara adat Suku Marind di Merauke dapat mencapai Rp 20.000,00 per ikat-ikatan (gambar 7) dan Rp 100.000,00 per rumpun kecil (gambar 8) dan $\mathrm{Rp} 500.000,00$ per rumpun besar (gambar 9) di kampung-kampung yang letaknya jauh dari kota dan dapat mencapai
Rp 500.000,00 sampai Rp 1.000.000,00 bahkan dapat mencapai Rp 1.500.000,00 di kampung-kampung yang dekat dengan kota Merauke ibukota kabupaten Merauke:

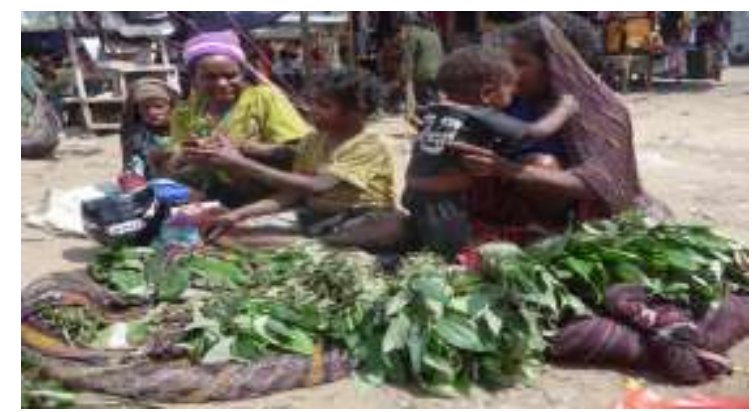

Gambar 6. Ikatan Daun Tumbuhan Diwoka

(Piper macropiper Pennant.) yang di jual di Pasar Tradisional "Sinakma" di Wamena.

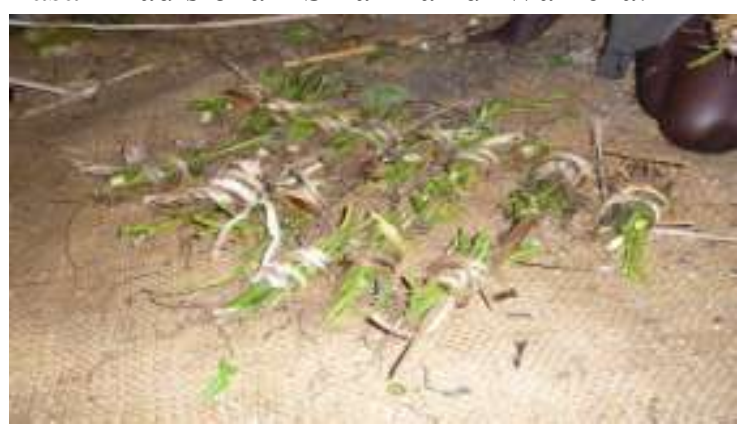

Gambar 7. Ikatan-ikatan Batang Tanaman Wati (Piper methysticum Forst.) (foto oleh KMB Kameubun).

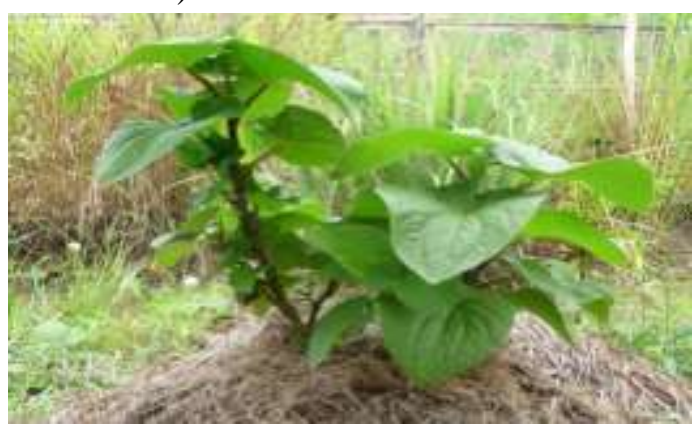

Gambar 8. Rumpun Kecil dari Tanaman Wati (Piper methysticum Forst.) (foto oleh KMB Kameubun).

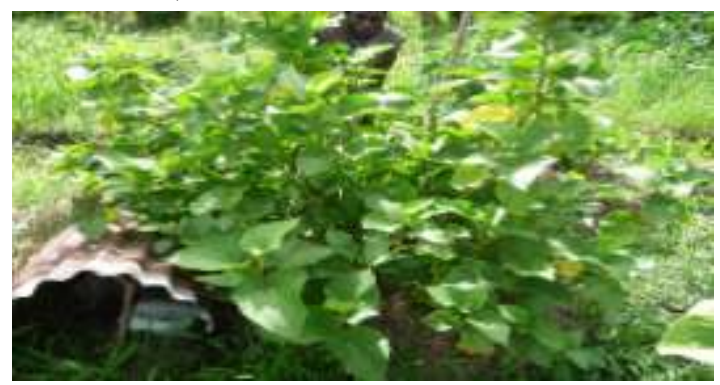

Gambar 9. Rumpun Besar dari Tanaman Wati (Piper methysticum Forst.) (foto oleh KMB Kameubun). 


\section{Konservasi}

Usaha konservasi tanaman Piper macropiperPennant. oleh masyarakat suku Dani belum nampak dalam kehidupan mereka sehari-hari. Mereka masih bergantung pada tanaman ini yang tumbuh dengan sendirinya dialam. Konservasi secara ex-situ belum dilakukan oleh pemerintah maupun lembaga-lembaga swadaya masyarakat dan masyarakat lokal.

Habitat asli dari tanaman ini terancam terganggu karena ulah manusia yang selalu menebang pohon-pohon dan mengambil kayu hasil tebangan di hutan yang merupakan habitat tanaman Diwoka (Piper macropiper Pennant.).

Upaya untuk budidaya atau menanam kembali tanaman ini tidak dilakukan namun tanaman ini selalu diperjual belikan oleh masyarakat suku Dani di pasar tradisional. Kondisi seperti ini bila dibiarkan tanpa adanya usaha konservasi secara alami maka akibatnya populasi tanaman ini akan berkurang dari waktu ke waktu. Bila hal ini tidak dicegah maka akan mengarah kepada keancaman kepunahan dihutan alam Wamena.

Tanaman ini dianggap perlu untuk dikonservasi secara ex-situ. Priyono dan Jamal (2008) telah melakukan riset perbanyakan tanaman Piper macropiper dari Wamena dengan cara perundukan. Humus hutan merupakan media tanam terbaik pada perbanyakan dengan cara perundukan, ruas batang tua berpengaruh positif pada media tanam sekam campuran. Hutan merupakan habitat yang sangat baik untuk tanaman Piper macropiper Pennant. Oleh karena itu tumbuhan ini sangat membutuhkan hutan sebagai tempat tumbuhnya.

\section{SIMPULAN DAN SARAN \\ SIMPULAN}

Tanaman Diwoka yang dikenal oleh masyarakat suku Dani diketahui nama ilmiahnya yaitu Piper macropiper Pennant dimanfaatkan sebagai sayur, bumbu dan obat Sariawan, Malaria, dan untuk memacu napsu makan oleh masyarakat suku Dani, Wamena Propinsi Papua.

\section{SARAN}

Lada atau Merica (Piper nigrum L.) akan membantu dalam meningkatkan pendapatan ekonomi masyarakat suku Dani dan lainnya di Wamena.

\section{UCAPAN TERIMA KASIH}

Terimakasih kami sampaikan kepada suku Dani, Wamena Propinsi Papua yang telah berkontribusi dalam penelitian.

\section{DAFTAR PUSTAKA}

[EOL] Encyclopedia of life. http://www.discoverlife.org/mp/20m ?map=Piper+macropiper.

Gardner, R.O, 2006, Piper (Piperaceae) in the Philippine islands: the climbing species, Journal of plant taxonomy and plant geography, BLUMEA, Vol, 51, no. 3;

Kameubun, K.M.B, 2003, Aspek Botani dan Etnobotani Wati (Piper methysticum Forst.) dalam 
Jurnal Ilmu Pendidikan Indonesia 8 (1) : 37 - 45 | 45

Kehidupan Suku Marind Kabupaten Merauke. Tesis Magister, IPB;

Kameubun, K.M.B. 2014, Indigenous Knowledge, morphological variation and genetic diversity of Kava (Piper methysticum Forst.) in Merauke, Рариа, Indonesia, Disertasi, GeorgAugust-Universitat, Goettingen, German;

Priyono, S.H. dan Y. Jamal, 2008, Konservasi Piper miniatum Bl.
Dengan perbanyakan cara perundukan; ekstraksi dan uji aktifitas antiradical bebas DPPH, dan antidiabetik. Jurnal Teknologi Lingkungan, Volume 9. Nomor 3;

Walujo, E.B, 1998, Etnobotani Metode Penelitian Baru Penggabungan Antara Konsep Ilmu-ilmu Sosial dan Ilmu Biologi. Prosiding Seminar Nasional Etnobotani III, 5 - 6 Mei 1998. 